\title{
TRADUÇÃO COMO GESTO INACABADO: REFLEXÕES SOBRE O ATO CRIATIVO DO TRADUTOR
}

Yan Patrick Brandemburg Siqueira

\begin{abstract}
RESUMO: Pretende-se compreender como a ação de um tradutor literário é também um ato criativo, complexo, e não mecânico, no tratamento com a linguagem. Dessa maneira, a intenção é compreender esse processo de uma maneira geral, contudo, sem privilegiar o estudo de um autor especifico. Utilizaremos a Crítica Genética de Literatura e os Estudos Descritivos da Tradução como amparos teóricos das argumentações direcionadas a compreender o trabalho do tradutor como um Gesto Inacabado, conceito de Cecília Almeida Salles. O objetivo é, portanto, aproximar as reflexões sobre o fazer do escritor com o do tradutor, ressaltando, para isso, suas semelhanças e dilemas.
\end{abstract}

Palavras-chave: Crítica genética de literatura. Estudos Descritivos da tradução. Tradução.

\section{INTRODUÇÃO}

Cecília Almeida Salles (2013, p. 33) define a criação artística como um processo de representação, uma metamorfose contínua. O esforço do artista é o mesmo de um artesão tentando criar determinada forma ainda inexistente, mas real no imaginário do artista. Criar é um projeto nebuloso, porque incerto: escrever é como perseguir uma miragem na tentativa de conseguir sua concretização (SALLES, 2013, p. 36). Neste interim, a obra de arte é, de certa forma, dessacralizada por ser encarada como um "produto" não finalizado, já que outras múltiplas versões são consideradas. Isso ocorre na medida em que são apresentadas as dificuldades de criação, as diferenças entre o projeto inicial e final e como, muitas vezes, o caminho percorrido é longo e/ou lento: escrever exige paciência e revisão quase ininterrupta.

Com o objetivo de comparar o ato criativo do escritor para com o do tradutor, consideraremos somente a tradução literária, diferenciando-a da dita tradução técnica. Ivone Castilho Beneditti (2003, p. 22) admite que a divisão é bastante discutível, principalmente, se considerarmos questões de mercado, como a remuneração dos tradutores que parece não distinguir os dois tipos de tradução. Entretanto, Beneditti concorda que há diferenças particulares. $O$ tradutor literário preocupa-se com a metáfora, com as construções sintáticas 
inovadoras: o cuidado com o signo é fundamental na tradução, por exemplo, de uma poesia. Já a tradução técnica é demarcada muito mais por uma especificidade terminológica: podemos citar a tradução de textos da área jurídica como exemplo.

Isso posto, em que pontos se assemelham e diferenciam o ato criador do escritor para com o ato tradutório? Sergio Romanelli (2010, p. 01) afirma: traduzir é criar. Mesmo considerando as características particulares de cada processo, os procedimentos, se não são os mesmos, são mais semelhantes que diferentes. Estudos perpassam o mesmo caminho na tentativa de legitimar o trabalho do tradutor, afirmando sua importância na manutenção das obras de arte e sua inserção em diferentes momentos históricos. Isso vai de encontro às ideias que acreditam na impossibilidade de autonomia do texto traduzido em relação ao seu original, por consequência, de seu tradutor para com o escritor de origem.

A tradução é vista enquanto um gesto inacabado na medida em que não nos interessa seu produto final a priori, mas, sim, o percurso trilhado pelo tradutor, suas intenções, opções, escolhas e estudos feitos para traduzir determinado texto literário. $\mathrm{E}$, principalmente, importam as reflexões dadas a partir de vários depoimentos sobre o ato criativo do tradutor e do escritor literário.

Romanelli acredita que os estudos de Crítica Genética (CG) podem auxiliar os Estudos Descritivos da Tradução (EDT) na tentativa de reconstituir o que se passa na mente do tradutor enquanto realiza seu trabalho. Assim, entendendo que o procedimento tradutório é muito mais complexo do que comumente se pensa. Necessário destacar que serão privilegiados elementos do campo da CG que tornam este estudo diferente daqueles que investigam o processo tradutório em si mesmo. Além disso, o propósito deste artigo não é de escolher um autor específico e tentar visualizar a ocorrência dessa teoria, no entanto, objetiva-se entender de maneira geral como o tradutor também é um escritor, questionar suas características em comum e em que medida ele se inventa dentro da obra de origem produzindo um novo texto, contextualizandoo em seu momento histórico. Para Marie Passos (2011, p. 02), esse tipo de pesquisa almeja "demonstrar que o tradutor é um escritor e que é passando pela crítica genética que se pode chegar a essa conclusão, posto que seja na crítica genética que se podem obter provas do seu processo de trabalho".

\section{CRÍTICA GENÉTICA E ESTUDOS DESCRITIVOS DA TRADUÇÃO}

Segundo Philippe Willemart (1993, p. 16), a CG da literatura se interessa pelo prototexto, conceito base dessa vertente. Para o analista, as diversas versões do mesmo texto são postas lado a lado, ignorando o registro temporal de modo que "uma versão não será vista como causa da seguinte ou consequência da anterior" (WILLEMART, 1993, p. 18-19). Assim, o produto final, ou seja, a obra publicada, não é mais importante que as versões anteriores e os rascunhos. Entende-se que "a última vontade do autor valeria 
tanto quanto a primeira, a segunda ou a penúltima" (WILLEMART, 1993, p. 12). Dessa forma, o conceito de prototexto não abarca, necessariamente, a origem da obra literária, mas todo o processo.

Lê-se a obra a partir dos rascunhos de seu autor, afirmando que essas alternativas se equivalem. A CG se configura na crise da modernidade clássica ao relativizar a obra pronta e consagrada. Com isso, cada versão da obra possui autonomia: o ânimo autoral é substituído pelas instâncias narrativas, isto é, a obra publicada não servirá como base única para a interpretação. Dispondo de materiais raramente explorados, a CG abre espaço para uma pluralidade de sentidos de tudo que era visto enquanto sistema e compreendido como uma estrutura fixa (WILLEMART, 1993, p. 12-13). Sendo assim, pode-se, por exemplo, entender que aquilo que o escritor apaga pode ser uma concessão ao gosto dominante de determinado círculo literário, um gesto de obediência, seja moral, religioso ou científico. Ler os rascunhos é tentar compreender a gênese da criação literária de um autor e identificar que cortes ou acréscimos, no decorrer das diferentes versões do texto, podem ser interpretados.

A CG estuda um movimento e não somente a imobilidade de um produto fixado; não objetiva esclarecer as camadas obscuras do escrito, mas a compreender o processo dinâmico que é a atividade escrita (PASSOS, 2007, p. 257). Uma das vertentes da relação entre CG e EDT é que, quando possível, o tradutor se introduza no laboratório do escritor, refazendo, ou, no mínimo, conhecendo os passos trilhados pelo escritor que se pretende traduzir. Apropriando-se dos bastidores de criação literário, é possível inserir o processo tradutório no mesmo registro que o processo de criação. Assim colocado, Marie Passos (2007, p. 258) conclui que do mesmo modo como é possível conhecer o percurso trilhado pelo escritor, também é possível "dizer que o material genético de um texto traduzido nos leva ao universo criativo do tradutor".

Romanelli (2010, p. 6) acredita que o estudo dos manuscritos deixados pelos tradutores revelaria um "modus operandi de um tradutor, que é similar modus operandi do autor, revelando um preciso método de criação artística". Observar os manuscritos, os depoimentos e o processo tradutório da mesma forma que o processo de criação do escritor sinaliza uma forma de legitimar o trabalho árduo e criativo da tradução. O propósito não é de destituir a figura do autor, mas colocá-lo no mesmo patamar do tradutor. O texto traduzido não se configura como uma reprodução fiel do primeiro, mas como uma concretização de uma de suas possibilidades (PASSOS, 2007, p. 262). É possível questionar, portanto, a ideia equivocada de que literatura traduzida não seja literatura, ou de que o tradutor não seja também um escritor.

\section{O GESTO INACABADO}

Cecilia Almeida Salles (2013) estuda o processo criativo não só de escritores, mas de artistas em geral, como um gesto inacabado buscando em rascunhos, manuscritos e entrevistas compreender o ato criativo. Assim, a 
criação é entendida como esse processo incompleto por ser a própria obra vista como um estado de continua metamorfose (SALLES, 2013, p. 33). Várias facetas da mesma arte são postas lado a lado com o objetivo de compreender o percurso criado e traçado pelo artista durante sua produção. No decorrer da atividade criadora, insere-se a tradição literária, os recursos artísticos, a insatisfação com a criação, o projeto poético do autor, o uso da memória, da imaginação e da observação. Com fins de estudo, é possível traçar parâmetros a partir de depoimentos de vários escritores, buscando suas semelhanças e diferenças. Desta maneira, mapeamento o movimento criador, de forma a entender seu funcionamento.

Um dos conceitos para o entendimento do fazer literário como gesto inacabado é o projeto poético. Salles (2013, p. 46) o define como um conjunto de princípios éticos e estéticos que orientam a atividade do artista. Esse conglomerado de concepções é mutável e se concretiza no fazer artístico de cada obra. Na literatura, é como se em cada novo livro o escritor se lançasse numa tentativa de concretizar esse grande projeto e, por isso, cada obra anterior seria um rascunho ou tentativa de realizá-lo. Assim sendo, essas tendências poéticas orientam a criação de uma obra específica ao mesmo tempo que realiza o julgamento e avaliação de produções anteriores.

Outra característica constante no fazer artístico é o descontentamento com a própria criação - intitulada por Mario de Andrade de a doença estética da imperfeição (SALLES, 2013, p. 38). Após várias alterações e a publicação de um livro, o escritor se projeta a escrever outro como forma de saciar essa insatisfação que é, praticamente, inerente ao fazer artístico. É como se o projeto poético não fosse possível ser alcançado, até mesmo pelo caráter movediço, pois novas necessidades surgem e alteram o rumo da criação enquanto ela é gerada. Isso obrigaria o artista a criar outra obra para saciar essas novas vontades. $O$ artista é plenamente insatisfeito e, por isso mesmo, move-se a escrever outro livro como forma de cumprir o que o anterior não conseguiu.

Os relatos de vários escritores também exemplificam essa insatisfação e uma tentativa de concretização do projeto poético: François Mauriac (1982, p. 28) diz que sempre começa seus romances com o intuito que fosse desnecessário escrever outro. A cada novo livro, sentia-se como que se estivesse escrevendo sua obra-prima. No entanto, devido a desajustes que ocorreram em todas as suas publicações, retornou a escrever outro, como um homem que estivesse a recomeçar sua vida. William Faulkner (1982, p.37) afirmava que, certamente, se pudesse reescrever todas suas obras o faria melhor - e essa é a condição mais saudável para o artista, pois é desta maneira que o escritor continuará a trabalhar para atingir o que pretende objetivo que, para alguns, o artista jamais conseguirá. Caso conseguisse realizar esse projeto, tornando reais todas as suas ambições para uma obra, segundo Faulkner, nada mais lhe sobrará e só lhe restaria cortar a garganta. 
Para Romanelli (2010, p. 04), as pesquisas aplicando os conceitos e procedimentos de CG nos EDT demonstram que para um escritor/tradutor sua obra dificilmente está terminada, e mesmo após publicada continua sendo insatisfatória - o artista/tradutor encara o descontentamento do ato criador. Um exemplo específico é dado com o estudo de Passos (2007, p. 265) sobre a tradução que Caio Fernando Abreu fez do poema "Fever 103" de Sylvia Plath. O prototexto é formado de três folhas. Sua primeira versão é marcada pelo jorro tradutório em que o escritor parece não querer interromper o fluxo da escrita. O que indica a intenção de que a primeira tradução é marcada pela significância, pela importância de contextos de semânticos de uma cultura para outra. No resto do processo, Abreu demonstra-se insatisfeito e corrige palavras, evita repetições; procurando enriquecer o texto, revisita o texto de origem, retornando para a escrita. Enquanto no primeiro impulso escrito pouco se intervém, o restante do processo é marcado por rasuras e correções em busca de uma estrutura harmoniosa e textualização do ritmo (PASSOS, 2007, p. 267-268). Por fim, Passos conclui que a tradução de Abreu é marcada por uma trajetória criativa de exposição e de eclosão, o que o aproxima do texto e manuscritos de Sylvia Plath em seu processo árduo de criação.

\section{COMPARANDO DILEMAS: A ORIGINALIDADE DO ESCRITOR E A FIDELIDADE DO TRADUTOR}

As marcas singulares do artista quando em contato com a tradição literária implicam na questão da originalidade da obra. Fato esse que orienta tanto o trabalho do escritor, como o do tradutor. Amilcar Bettega (2012, p. 12) acredita que nunca se conta a mesma história da mesma maneira, pois o ato de contar já é, por si só, uma deformação. O autor destina seu estudo ao campo da ficção, entretanto, pode-se ampliar a afirmação e expandi-la aos demais textos literários quando afirma que "a originalidade não está no tema, mas no que se faz dele" (2012, p. 13). Ainda assim, é possível ser completamente original, mesmo usando de um tema já exposto na tradição literária? Bernardo Moraes (2012, p. 53) responde categoricamente que não, e afirma que criar uma obra essencialmente original é ambição de um tolo. Para o escritor, o próprio conceito de originalidade é desgastado e já não perpassa a ideia de criação de algo novo, mas, sim, de reorganização. Isto é, não se deve pensar em ignorar a tradição, o que é inviável, ela estará presente de alguma forma, mas de organizá-la de um modo que nunca tenha sido feito antes, e é essa a possibilidade de criar uma arte original:

Admitir a inexistência de completa originalidade pode parecer uma perda para o autor. É, entretanto, um alívio criativo: livre da necessidade de negar seus antepassados - a angústia da influência - 0 autor pode juntar suas preferências, influências e objetivos e criar seu próprio caminho (MORAES, 2012, p. 54). 
O problema de originalidade é maior ainda quando se insere o debate no campo dos estudos tradutórios. Além disso, percebe-se uma semelhança entre os dois atos: o conflito do escritor reflete em sua preocupação com a herança da tradição literária, do poder do cânone e incapacidade de criar algo realmente novo e original. Já para o tradutor, o texto de origem é a tradição. Construir algo relativamente novo ou respeitar plenamente o original? Adail Sobral aponta esse um dilema marcado no ato tradutório:

A atividade do tradutor pode ser pensada com um ato marcado pelo dilema de evitar tanto impor o modo de ser de uma data cultura, repetindo palavras e metáforas que vêm de outra cultura, como impor ao texto traduzido o modo de ser de sua própria cultura, matando o estilo e as ênfases do conjunto. Logo, manter esse difícil equilíbrio é necessariamente um ato ético (SOBRAL, 2003, p. 203)

Assim, cabem os questionamentos: o tradutor deve ser fiel ao texto de origem, assimilando todas suas construções e reproduzindo a possível totalidade do texto original, bem como seu estilo e possível fluência original? Ou deve pensar-se como um escritor de um novo texto, atualizando-o como um sujeito em seu momento histórico e cultural? Conseguirá o tradutor transportar conteúdos de uma língua para a outra, numa função quase mecânica, transportando significados sem, com isso, interpretá-los? Se isso fosse possível, não teríamos uma tradução ideal para um só texto de origem?

Por mais que se deseje chegar ao texto fonte, devemos levar em consideração que não obtemos a mesma carga histórica e social dele, mas traduzimos nossa interpretação a partir de nossa leitura de mundo condicionada ao momento histórico em que vivemos. Toda tradução é uma das possíveis versões de um texto original, uma de suas possibilidades, uma de suas potencialidades. Traduz-se não o texto, mas uma visão daquele texto, uma possível interpretação guiada pela visão de mundo e momento histórico do tradutor (CARVALHAL, 1993, p. 50).

Sobral (2003, p. 203) além de apontar sobre o dilema de fidelidade com o texto de origem, apresenta outro problema quanto a tradução: a visibilidade do tradutor. $\mathrm{O}$ problema está na prática de considerar a individualidade como subjetividade, uma expressão psíquica individual e única. Se a originalidade e individualidade estão presentes no texto de origem, caberia ao tradutor trabalhá-las em sua língua de destino. Mas o tradutor não repete, ele transcria: o tradutor não é uma simples máquina de transmissão de conteúdos de uma língua para outra, ele trabalha, pesquisa e reelabora a obra conforme sua própria individualidade e criatividade. Para Arrojo (1997, p. 36), "quando equiparamos a tradução ou a leitura de um poema à sua criação, fica claro que exigimos de seu leitor ou tradutor uma sensibilidade e um talento semelhantes aos que tradicionalmente se exigem dos poetas". Sendo assim, repetindo a 
afirmação de Romanelli, traduzir é criar - e criar a partir de sua interpretação do texto de origem.

O problema é ainda maior se pensamos na tradução de textos literários, pois passamos a dar significado a todas associações e possíveis construções do texto de origem para construir uma interpretação coerente com a tradução pretendida. Cada tradutor fará uma tradução condicionada ao momento histórico em que vive - o que permite que as mesmas obras sejam revisitadas de formas distintas. Com isso, ao permitir uma nova versão, um novo destino, uma transposição, a tradução colabora com um prolongamento do texto dentro da história, bem como a manutenção dela (CARVALHAL, 1993, p. 51). A reflexão teórica sobre esses fatos permite ao tradutor entender que um mesmo texto literário pode ser traduzido de diferentes formas e que não, necessariamente, uma é melhor que a outra (BRITTO, p. 93).

Comparando a tradução literária e a escrita de textos literários, Tania Franco Carvalhal (1993, p. 47) explica que uma diferença está entre seus pontos de partida: na criação livre seu início é diverso, já na tradução, por mais abrangente o método e a técnica, parte-se sempre da leitura do texto de origem. $\mathrm{O}$ ato criativo de um escritor tem também como pressuposto a tradição literária, toda a história e literaturas produzidas antes que o escritor pense em criar algo novo. O escritor tem atrás de si, e ao seu lado, toda uma produção literária e artística que ele se apropria, de alguma forma, consciente ou inconsciente, para elaborar sua própria literatura. Enquanto na tradução o ponto de partida é a leitura do texto de origem, o que direciona o processo tradutório.

Outra questão é a tradução de um poema: tarefa quase impossível quando se pensa na indissolúvel associação entre forma e conteúdo. Paulo Henriques Britto (2003, p. 90) entende que se espera do tradutor literário algumas das qualidades que caracterizam o escritor profissional, como o apuro com o estilo e a sensibilidade artística. Nisto reside uma peculiaridade de tradução literária: o cuidado com o significante. Mário Laranjeira (2003, p. 120) acredita que a primazia na tradução literária reside na prudência com a sonoridade, no ritmo do verso, enquanto uma tradução não-literária privilegia o significado, o conteúdo e, portanto, a informação.

Para Raimundo Carvalho (2014, p. 109), a tradução é por si só uma bofetada no rosto das musas, pois revela o caráter humano no tratamento poético. Escrever exige reescrever: não há musas que sopram ao ouvido do poeta versos prontos - e muito menos o tradutor conta com tal auxílio. Como afirma Passos (2011, p. 04), o tradutor não é um simples intermediário entre as duas línguas. $O$ ato de redobrar o texto de origem em sua língua de destino não existe, e o pressuposto que "toda a tradução é uma má tradução" é um mito. Textos não são como cargas a serem transpostas de um lado para o outro. Neste intervalo entre duas culturas, insere-se o ato criativo do tradutor, que se torna escritor. 
O ato de traduzir uma poesia também é o de criar poesia, pois o trabalho não é monótono ou apenas cerebral, mas envolve todo o corpo do tradutor (CARVALHO, 2014, p. 110). Assim como o escritor lida com a tradição literária e preocupa-se em trazer uma matéria nova para sua literatura, o tradutor se vê como uma sombra do texto de origem, dividido entre a fidelidade com esse texto ou a criação de algo novo ou, no mínimo, diferente do original que dialogue com a própria cultura em que o tradutor se insere.

A literatura como arte da palavra necessita de atenção aos detalhes. $O$ trabalho com o poético exige que a palavra saia de seu estado de dicionário e produza diferentes sentidos daquele signo arbitrário de origem. Assim sendo, produz-se a palavra poética como signo motivado, o que faz com que "o sentido necessariamente se produza nos interstícios do tecido sonoro que o poema projeta no ar através da voz que o performa" (CARVALHO, 2014, 107). Tanto o escritor como o tradutor trabalham com dificuldades inerentes ao processo de criação. Mais uma vez, o ato criador é o "gesto inacabado" de Salles, e o artista, incluindo-se o tradutor, é aquele que tenta tornar real o que se passa somente em sua mente - é um perseguidor de miragens.

\section{CONCLUSÕES}

Optou-se sobre uma reflexão sobre o ato criativo do tradutor como forma de legitimar sua importância. O recorte, utilizando como suporte teórico a Crítica Genética de Literatura, poderia ser outro, pois o campo é vasto. Entretanto, designou-se aquele em que se verificaram possíveis diálogos, de modo a exemplificar melhor as semelhanças e diferenças entre os depoimentos de escritores para com os dos tradutores.

Ademais, verificou-se que a tradução literária é responsável, de certa forma, pela manutenção do cânone e da história da literatura, possibilitando sua atualização e renovação. Sendo assim, o tradutor não é um simples mediador entre duas línguas, mas além de um intérprete de duas culturas, entre dois sujeitos, é também um escritor e, cabe a ele, portanto, interceder, da melhor forma possível, e decidir criativamente os dilemas do ato tradutório - e que também é artístico.

Com essa importância, ainda é necessária uma maior visibilidade ao tradutor literário. Afinal, traduzir literatura é um trabalho que requer comprometimento e inventividade: não há um texto ideal a ser alcançado, mas possibilidades que variam de acordo com a engenhosidade e o repertório do tradutor. Isso posto, o mito de um suposto trabalho mecânico e pouco reflexivo no ato tradutório é abolido e, em seu lugar, o tradutor é visto como um escritor. Em síntese, como afirma Romanelli, traduzir é criar.

Dito ainda de outra maneira, o tradutor é aquele que penetra surdamente no reino das palavras e convive com os textos - dos outros - para reescrevêlos criativamente. Logo, como escreve Carlos Drummond de Andrade no poema "O lutador", mesmo sabendo que lutar com as palavras é a luta mais vã, o tradutor, assim como o poeta, não desiste, pois sabe que desse combate 
nascerá um novo texto. E se o descontentamento é o que move o artista, a intitulada doença estética da imperfeição de Mario de Andrade, é o duelo que vale a pena.

\title{
TRANSLATION AS GESTURE UNFINISHED: REFLECTIONS ON THE CREATIVE ACT OF THE TRANSLATOR
}

\begin{abstract}
This paper intends' to understand how the action of literary translator is also a creative, complex, and not mechanical act, in the treatment with the language. In this way, the intention is to understand this process in a general way, however, without privileging the study of a specific author. We will use the Genetic Critique of Literature and the Descriptive Translation Studies as theoretical support of the arguments directed to understand the work of the translator as an Unfinished Gesture, concept of Cecilia Almeida Salles. The aim is, therefore, to approach the reflections on the writer's doing with that of the translator, highlighting, for this, their similarities and dilemmas.
\end{abstract}

Keywords: Genetic criticism of literature. Descriptive Translation Studies. Translation.

\section{REFERÊNCIAS}

BENEDETTI, Ivone. Prefácio. BENEDETTI, Ivone; SOBRAL, Adail (org). Conversas com tradutores: balanços e perspectivas da tradução. São Paulo: Parábola. 2003.

BERLINER, Claudia. Conversas com tradutores: balanços e perspectivas da tradução. São Paulo: Parábola. 2003, p. 75-78.

BETTEGA, Amilcar. Da página em branco à página nova. In: ASSIS BRASIL, Luiz Antonio de (Coord.); DOVAL, Camila Canali; SILVA, Camila Gonzatto da; SILVA, Gabriela (Org.). A escrita criativa: pensar e escrever literatura. Porto Alegre: EDIPUCRS, 2012, p. 11-15.

BRITTO, Paulo Henriques. Conversas com tradutores: balanços e perspectivas da tradução. São Paulo: Parábola. 2003, p. 89-98.

CARVALHAL, Tania Franco. A tradução literária. In: Organon, Porto Alegre, vol. 7 , n. 20, 1993, p. 47-52.

CARVALHO, Raimundo. Tradução da poesia latina clássica: uma tradição sempre renovada. 2014. Disponível em: < 
http://ojs.c3sl.ufpr.br/ojs/index.php/letras/article/view/35368/23104> Acesso em: 27 de mai. 2014.

FAULKNER, William. Escritores em ação: as famosas entrevistas à "Paris Reviem". Rio de Janeiro: Paz e Terra, 1982, p. 35-58.

MAURIAC, François. Escritores em ação: as famosas entrevistas à "Paris Reviem". Rio de Janeiro: Paz e Terra, 1982, p. 21-34.

MORAES, Bernardo. A teia criativa: notas sobre influências, referências e originalidade. In: ASSIS BRASIL, Luiz Antonio de (Coord.); DOVAL, Camila Canali; SILVA, Camila Gonzatto da; SILVA, Gabriela (Org.). A escrita criativa: pensar e escrever literatura. Porto Alegre: EDIPUCRS, 2012, p. 53-56.

NETTO, HAROLDO. Conversas com tradutores: balanços e perspectivas da tradução. São Paulo: Parábola. 2003, p. 133-147.

PASSOS, Marie-Hélène Paret. Crítica genética e tradução literária: uma interdisciplinaridade. In: PINO, C. C. A. (Org.). Criação em debate. São Paulo: Humanitas, 2007, p. 255-268.

PASSOS, Marie-Hélène Paret. Da Crítica Genética à Tradução Literária: o caminho da (re) escritura. 2011. Disponível em: < http://incubadora.periodicos.ufsc.br/index.php/intraducoes/article/view/1802> Acesso em: 27 de mai. 2014.

ROMANELLI, Sergio. Crítica genética e estudos descritivos da tradução: um exemplo de interdisciplinaridade. In: PINO, C. C. A. (Org.). Criação em debate. São Paulo: Humanitas, 2007, p. 269-282.

ROMANELLI, Sergio. Processo criativo e tradução. 2010. Disponível em: < http://incubadora.periodicos.ufsc.br/index.php/intraducoes/article/view/1670/193 9> Acesso em: 27 de mai. 2014

SALLES, Cecília Almeida. Gesto inacabado: processo de criação artística. $6^{a}$ ed. São Paulo: Intermeios, 2013.

SOBRAL, Adail. Posfácio. In: BENEDETTI, Ivone; SOBRAL, Adail (org). Conversas com tradutores: balanços e perspectivas da tradução. São Paulo: Parábola. 2003, p. 201-214.

WILLEMART, Philippe. Universo da criação literária. São Paulo: Editora da Universidade de São Paulo. 1993. 